\title{
ARRANJO ESPACIAL DO VIRA-CABEÇA DO FUMO EM ARAPIRACA, ESTADO DE ALAGOAS*
}

\section{JEFFERSON N. SILVA**, SAMI J. MICHEREFF***, GILVAN PIO-RIBEIRO \& GENIRA P. ANDRADE}

Área de Fitossanidade, Departamento de Agronomia, Universidade Federal Rural de Pernambuco, CEP 52171-900, Recife, PE, Fax: (081) 3302-1205, e-mail: michereff@uol.com.br

(Aceito para publicação em 28/08/2001)

Autor para correspondência: Sami J. Michereff

SILVA, J.N., MICHEREFF, S.J., PIO-RIBEIRO, G. \& ANDRADE, G.P. Arranjo espacial do vira-cabeça do fumo em Arapiraca, estado de Alagoas. Fitopatologia Brasileira 26:721-725. 2001.

\section{RESUMO}

O vira-cabeça do fumo (Nicotiana tabacum), causado pelo Groundnut ringspot virus (GRSV), do gênero Tospovirus, tem sido observado em alta incidência em determinadas áreas da região fumageira do agreste do estado de Alagoas. O arranjo espacial da doença foi analisado em duas áreas de plantio (A e B), formadas por quatro parcelas cada, localizadas no município de Arapiraca. As parcelas foram avaliadas semanalmente, sendo efetuado o mapeamento espacial de plantas sadias e com sintomas de vira-cabeça, bem como determinada a incidência da doença, representada pelo número de plantas com sintomas em relação ao total de plantas avaliadas. Pelas análises de "ordinary runs" e autocorrelação espacial, foi constatada a predominância do arranjo aleatório de plantas doentes, embora tenha sido detectada agregação em alguns casos. Embora não se descarte a possibilidade de mudas infetadas terem influenciado no arranjo da doença, a hipótese mais provável é que as infecções ocorreram principalmente pelo inóculo primário transmitido por tripes virulíferos entrando nas parcelas, oriundos de reservatórios externos.

Palavras-chave adicionais: Groundnut ringspot virus, GRSV, Nicotiana tabacum, epidemiologia.

\section{ABSTRACT \\ Spatial pattern of spotted wilt of tobacco in Arapiraca, Alagoas, Brazil}

The spotted wilt of tobacco (Nicotiana tabacum), caused by Groundnut ringspot virus (GRSV), genus Tospovirus, has been observed with high severity in certain areas of the tobacco producing region of Alagoas. The spatial pattern of the disease was analysed in two areas (A and B), formed by four parcels each, located in the county of Arapiraca. The parcels were evaluated weekly by spatial mapping of healthy and spotted wilt tobacco plants, as well as by the disease incidence, represented by the number of plants with symptoms in relation to the total evaluated plants. Through the analyses of ordinary runs and spatial autocorrelation, a random pattern diseased plants was predominantly observed, although aggregation was also detected in a few cases. Although the possible effect of infected seedlings in the spatial pattern was not discarded, the most probable hypothesis is that the infections mainly occurred due to the primary inoculum transmitted by viruliferous thrips entering the parcels from external reservoirs.

\section{INTRODUÇÃO}

A região agreste do estado de Alagoas possui uma extensa área plantada com fumo (Nicotiana tabacum L.), onde o município de Arapiraca e localidades vizinhas destacam-se como principais produtores, com aproximadamente 30.000 ha plantados (IBGE, 2001), representando um importante papel sócio-econômico.

Em 1998, amostras de fumo, de outras plantas cultiva-

\footnotetext{
*Parte da Dissertação de Mestrado do primeiro autor. Universidade Federal Rural de Pernambuco. (2000)

**Bolsista da CAPES.

***B Bolsista do CNPq.
}

das e de ervas daninhas coletadas em Arapiraca apresentaram sintomas de mosaico, necrose das nervuras, crestamento, deformação foliar, encurvamento do ápice da planta para baixo e, algumas vezes, morte da planta. Após análise do material vegetal pelo teste de ELISA indireto, foi confirmada a infecção por Groundnut ringspot virus (GRSV), espécie pertencente ao gênero Tospovirus, cuja doença induzida é conhecida por vira-cabeça (Silva et al., 1999).

Os danos causados pelo vira-cabeça do fumo são extremamente variáveis e, no Brasil, dependendo da época do ano, a doença pode atingir $100 \%$ de incidência (Godoy \& Salgado, 1997). Na natureza, a transmissão dos tospovirus ocorre exclusivamente por ação de tripes (Thysanoptera: Thripidae), sendo relatadas atualmente nove espécies de tripes 
vetoras de tospovirus (Pozzer et al., 1996). A transmissão do vírus ocorre de maneira circulativa-propagativa que, adquirido por larvas de tripes de $1^{\circ}$ ínstar durante a alimentação em plantas hospedeiras infetadas, é transmitido por tripes adultos quando se alimentam em plantas sadias (Wijkamp et al., 1993; van de Wetering et al., 1996).

A utilização de medidas isoladas para o controle de vira-cabeça não propicia resultados satisfatórios, sendo necessário um conjunto de práticas como escolha da época de semeadura, localização de canteiros, isolamento da cultura, uso de inseticidas e eliminação de ervas daninhas, dentro e nas áreas circunvizinhas ao plantio (Pozzer et al., 1996; Godoy \& Salgado, 1997).

Apesar de o vira-cabeça do fumo ter sido registrado no Brasil há mais de 60 anos (Silberschmidt, 1937), são escassos os estudos epidemiológicos dessa doença aos níveis nacional e mundial.

Dentre os estudos necessários para a compreensão e manejo de patossistemas, destaca-se a análise da dinâmica espacial de epidemias. Os aspectos espaciais das epidemias, apesar de importantes, são geralmente menos óbvios que a dinâmica temporal e, por conseqüência, menos investigados (Jeger, 1990). A análise do arranjo espacial de plantas doentes tem possibilitado o entendimento de aspectos relacionados ao padrão do inóculo inicial, aos mecanismos de dispersão do patógeno, ao efeito de práticas biológicas e culturais, bem como ao efeito de fatores ambientais na infecção e dispersão de patógenos e doenças (Xiao et al., 1997). Várias técnicas podem ser utilizadas para caracterizar o arranjo espacial de plantas doentes, dependendo do tipo de dado coletado e do conhecimento sobre o local onde as observações foram realizadas (Jeger, 1990).

Em vista do desconhecimento sobre a dinâmica do viracabeça do fumo, o presente trabalho objetivou analisar aspectos espaciais da doença em duas áreas de plantio, localizadas no município de Arapiraca, agreste alagoano.

\section{MATERIAL E MÉTODOS}

O experimento foi conduzido em 1999, em duas áreas de plantio de fumo (A e B) localizadas no município de Arapiraca, onde no ano de 1998 foram verificadas elevadas incidências de vira-cabeça (Silva et al., 1999). O preparo do solo e a formação dos leirões foram realizados manualmente e os tratos culturais seguiram a rotina da região. As mudas utilizadas nos plantios pertenciam à cultivar Arapiraca e foram produzidas em canteiros nas propriedades. O transplante foi efetuado utilizando plantas com 30 dias, no espaçamento de $0,6 \times 1,2 \mathrm{~m}$. As duas áreas foram formadas por quatro parcelas, distanciadas de $30 \mathrm{~m}$, medindo 1.440 $\mathrm{m}^{2}$ cada uma e contendo 20 linhas x 100 plantas/linha. Nas bordas da área A havia plantios de caupi [Vigna unguiculata (L.) Walp.] sem sintomas de vira-cabeça, enquanto contíguos à área $\mathrm{B}$ havia plantios de alface (Lactuca sativa $\mathrm{L}$.) com sintomas da doença, cujos diagnósticos foram confirmados pelo teste de ELISA indireto. Durante o ciclo de cultivo foram efetuadas pulverizações de inseticidas para o controle de diversas pragas, sendo que na área $\mathrm{A}$ foram efetuadas seis aplicação do inseticida acefato (720 g/ha), a intervalos de dez dias, enquanto na área B foi efetuada a aplicação do inseticida imidacloprid ( $270 \mathrm{~g} / \mathrm{ha})$, logo após o transplante, bem como realizadas oito aplicações de acefato $(720 \mathrm{~g} / \mathrm{ha})$, a intervalos de sete dias.

Os dados de temperatura, umidade relativa do ar e precipitação total foram obtidos diariamente de estação meteorológica situada a cerca de $800 \mathrm{~m}$ das áreas experimentais.

Nas duas áreas de plantio, a partir de 44 dias do transplante, foi efetuado o mapeamento das plantas de fumo sadias e com sintomas de vira-cabeça, sendo que as plantas com sintomas duvidosos foram submetidas à análise sorológica com ELISA indireto para confirmação do diagnóstico. O arranjo espacial das plantas doentes em cada parcela e período de avaliação, foi determinado pelas análises de "ordinary runs" e análise de autocorrelação espacial. Com a análise de "ordinary runs" (Madden et al., 1982), foi investigada a existência de agregação entre plantas doentes imediatamente adjacentes dentro das linhas. Um "run" $(U)$ é descrito como a sucessão de uma ou mais plantas doentes ou sadias. O número esperado de "runs" $E(U)$ sob a hipótese nula de aleatoriedade é dado por $E(U)=1+[2 \mathrm{~m}$ $(N-m) / N]$, onde $m$ é o número de plantas com sintomas e $N$ é o número total de plantas por linhas combinadas. O desvio padrão de $U$, sob a hipótese de nulidade, é dado por $S(U)=\left\{[(2 m(N-m))(2 m(N-m)-N)] /\left(N^{2}(N-1)\right\}^{0,5}\right.$. Um teste normal padrão $Z$, onde $Z(U)=[U-E(U)] / S(U)]$, foi utilizado para determinar a significância da agregação de plantas doentes, sendo que valores de $Z$ menores que -1,64 $(P=0,05)$ indicam rejeição à hipótese de nulidade (arranjo aleatório), em favor da hipótese alternativa (arranjo agregado). Com os resultados obtidos, foram calculadas as porcentagens de linhas apresentando agregação entre plantas adjacentes dentro de cada parcela.

Para examinar a força e a orientação da agregação de plantas doentes entre quadriláteros, os dados de incidência da doença de cada parcela foram fracionados em quadriláteros de oito plantas (duas linhas x quatro colunas), totalizando 250 quadriláteros/parcela. Os dados de incidência nos quadriláteros foram analisados por autocorrelação espacial, utilizando-se o software LCOR2 (Gottwald et al., 1992). Por meio da localização espacial $[x, y]$ de cada quadrilátero em cada parcela e período de avaliação como dado de entrada para análise, foram calculados: os padrões de proximidade de posições lag positivamente (SL+) e negativamente correlacionados (SL-), determinados pelo número de lags $[x, y]$ significativamente maiores (SL+) ou menores (SL-) que o esperado pela chance a $\propto=0,05$; o tamanho do "cluster" principal, expresso pelo número de SL+ contíguos à posição lag $[0,0]$ que forma um grupo discreto; a força de agregação, determinada pelo número de SL+ no "cluster" principal dividido pelo número total de SL+; a orientação da agregação, definida pelo número de $\mathrm{SL}+$ dentro das linhas e entre linhas, 
definido pelo lag $[0,0]$.

Adicionalmente, foi determinada a incidência de viracabeça em cada parcela, pelo número de plantas com sintomas da doença em relação ao total de plantas avaliadas.

\section{RESULTADOS}

Pela análise de "ordinary runs", foi constatada a predominância do arranjo aleatório de plantas doentes em três parcelas $(1,3$ e 4$)$ da área $\mathrm{A}$ e em todas as parcelas da área B (Tabela 1). A porcentagem de linhas indicando agregação foi baixa, embora a agregação de plantas doentes tenha sido detectada em algumas situações. Pela análise de autocorrelação espacial, na área A não houve predomínio de um arranjo em particular, pois o arranjo aleatório ficou evidente na parcela 1 e o agregado na parcela 2 , enquanto as demais parcelas (3 e 4) apresentaram arranjo aleatório nas duas primeiras avaliações e agregado nas subseqüentes. $\mathrm{Na}$ área $\mathrm{B}$, o arranjo aleatório predominou em três parcelas $(1,2$ e 3), nas quais não foram detectadas forças de agregação e “cluster" principal. Em relação à orientação da agregação, quando presente, houve predominância de plantas doentes dentro das linhas, como observado nas parcelas 2, 3 e 4 da área $\mathrm{A}$, embora também tenha sido detectada a agregação entre linhas com menor intensidade, como na parcela 4 da área B (Tabela 3).

Considerando os dois métodos de análise do arranjo espacial, com exceção do verificado na parcela 4 da área $\mathrm{A}$ pela análise de "ordinary runs" $(r=0,97)$, não foram constatadas correlações significativas $(P=0,05)$ entre o aumento da incidência da doença e o grau de agregação de plantas doentes.

TABELA 1 - Arranjo espacial do vira-cabeça do fumo (Nicotiana tabacum) em Arapiraca (AL), em duas áreas de plantio (A e B) com quatro parcelas cada, analisado por "ordinary runs" e autocorrelação espacial

\begin{tabular}{|c|c|c|c|c|c|c|c|c|c|c|}
\hline \multirow{3}{*}{ Área } & \multirow{3}{*}{ Parcela } & \multirow{3}{*}{$\mathbf{D A T}^{\mathbf{a}}$} & \multirow{3}{*}{$\begin{array}{c}\text { Incidência }^{b} \\
(\%)\end{array}$} & \multirow{3}{*}{$\begin{array}{l}\text { Ordinary runs } \\
\text { Linhas com } \\
\text { agregação }(\%)\end{array}$} & \multicolumn{6}{|c|}{ Autocorrelação espacial } \\
\hline & & & & & \multicolumn{2}{|c|}{ Lags significantes $^{d}$} & \multirow{2}{*}{$\begin{array}{c}\text { Cluster } \\
\text { principal }^{\mathrm{e}}\end{array}$} & \multirow{2}{*}{$\begin{array}{c}\text { Força de } \\
\text { agregação }\end{array}$} & \multicolumn{2}{|c|}{ Efeitos $^{\mathrm{g}}$} \\
\hline & & & & & SL+ & SL- & & & Dentro linhas & Entre linhas \\
\hline \multirow[t]{16}{*}{ A } & 1 & 44 & 2,55 & 0 & 3 & 0 & 0 & 0,00 & 0 & 0 \\
\hline & & 51 & 4,20 & 0 & 0 & 0 & 0 & 0,00 & 0 & 0 \\
\hline & & 58 & 5,90 & 0 & 4 & 0 & 0 & 0,00 & 0 & 0 \\
\hline & & 65 & 6,90 & 0 & 6 & 0 & 0 & 0,00 & 0 & 0 \\
\hline & 2 & 44 & 3,35 & 95 & 2 & 0 & 2 & 1,00 & 2 & 0 \\
\hline & & 51 & 5,85 & 35 & 4 & 1 & 3 & 0,75 & 3 & 0 \\
\hline & & 58 & 7,35 & 50 & 5 & 2 & 3 & 0,60 & 3 & 0 \\
\hline & & 65 & 8,15 & 65 & 6 & 1 & 6 & 1,00 & 6 & 0 \\
\hline & 3 & 44 & 1,75 & 0 & 1 & 0 & 0 & 0,00 & 0 & 0 \\
\hline & & 51 & 2,85 & 0 & 2 & 0 & 0 & 0,00 & 0 & 0 \\
\hline & & 58 & 4,00 & 10 & 2 & 0 & 1 & 0,50 & 1 & 0 \\
\hline & & 65 & 5,50 & 10 & 2 & 0 & 1 & 0,50 & 1 & 0 \\
\hline & 4 & 44 & 2,00 & 0 & 2 & 0 & 0 & 0,00 & 0 & 0 \\
\hline & & 51 & 3,25 & 20 & 3 & 0 & 0 & 0,00 & 0 & 0 \\
\hline & & 58 & 4,30 & 30 & 1 & 0 & 1 & 1,00 & 1 & 0 \\
\hline & & 65 & 5,10 & 35 & 1 & 0 & 1 & 1,00 & 1 & 0 \\
\hline \multirow[t]{16}{*}{ B } & 1 & 44 & 13,05 & 0 & 1 & 1 & 0 & 0,00 & 0 & 0 \\
\hline & & 51 & 17,65 & 15 & 4 & 0 & 0 & 0,00 & 0 & 0 \\
\hline & & 58 & 20,80 & 5 & 3 & 1 & 0 & 0,00 & 0 & 0 \\
\hline & & 65 & 23,20 & 5 & 3 & 0 & 0 & 0,00 & 0 & 0 \\
\hline & 2 & 44 & 16,85 & 5 & 3 & 1 & 0 & 0,00 & 0 & 0 \\
\hline & & 51 & 20,90 & 0 & 5 & 1 & 0 & 0,00 & 0 & 0 \\
\hline & & 58 & 28,05 & 5 & 3 & 1 & 0 & 0,00 & 0 & 0 \\
\hline & & 65 & 31,85 & 0 & 2 & 1 & 0 & 0,00 & 0 & 0 \\
\hline & 3 & 44 & 15,60 & 35 & 0 & 2 & 0 & 0,00 & 0 & 0 \\
\hline & & 51 & 24,10 & 20 & 1 & 0 & 0 & 0,00 & 0 & 0 \\
\hline & & 58 & 27,15 & 0 & 2 & 1 & 0 & 0,00 & 0 & 0 \\
\hline & & 65 & 31,05 & 0 & 0 & 2 & 0 & 0,00 & 0 & 0 \\
\hline & 4 & 44 & 19,80 & 20 & 2 & 0 & 0 & 0,00 & 0 & 1 \\
\hline & & 51 & 22,45 & 40 & 3 & 1 & 2 & 0,60 & 0 & 2 \\
\hline & & 58 & 25,95 & 30 & 3 & 3 & 2 & 0,60 & 0 & 2 \\
\hline & & 65 & 38,00 & 10 & 4 & 2 & 3 & 0,75 & 1 & 2 \\
\hline
\end{tabular}

${ }^{\mathrm{a} D i a s}$ após o transplantio.

'Porcentagem de plantas com sintomas em relação ao total de 2.000 plantas em cada parcela.

${ }^{c}$ Calculado conforme Madden et al. (1982), considerando 100 plantas/linha e 20 linhas por parcela. Valores <50\% indicam aleatoridade de plantas doentes na parcela, enquanto $\geq 50 \%$ indicam agregação.

${ }^{\mathrm{d} N u ́ m e r o}$ de $[\mathrm{x}, \mathrm{y}]$ lags significativamente maiores (SL+) ou menores (SL-) que o esperado pela chance $\mathrm{a} \propto=0,05$.

eNúmero de SL+ contíguos à posição lag $[0,0]$ que forma um grupo discreto.

${ }^{\mathrm{f} N u ́ m e r o ~ d e ~ S L+~ n o ~ c l u s t e r ~ p r i n c i p a l ~ p e l o ~ n u ́ m e r o ~ t o t a l ~ d e ~ S L+. ~}$

gNúmero de SL+ dentro das linhas e entre linhas, definido pelo lag $[0,0]$. 
F.N. Silva et al.

\section{DISCUSSÃO}

Os arranjos espaciais de plantas com viroses são influenciados pela interação de vários fatores, incluindo o ambiente e os vetores (Madden et al., 1982). Embora descrições estatísticas não propiciem, por si próprias, uma explanação dos mecanismos responsáveis pelos arranjos espaciais (Campbell \& Madden, 1990), arranjos agregados de plantas doentes sugerem que houve disseminação planta a planta ou que o inóculo estava espacialmente agregado, enquanto arranjos aleatórios indicam que o patógeno não foi disperso ao longo da linha, ou que se foi disperso ao longo da linha, não induziu sintomas de maneira agregada (Campbell et al., 1984). Quanto à disseminação, arranjos agregados são mais caracteristicamente associados com fontes de inóculo próximas, ou mesmo, dentro de populações do hospedeiro, enquanto arranjos aleatórios geralmente resultam do inóculo chegando a uma população de plantas de uma fonte distante ou de material de plantio infetado (Burdon, 1987).

A predominância do arranjo aleatório de plantas doentes indica que a infecção das plantas de fumo com GRSV pode ter sido originária de uma fonte exógena à área de plantio ou decorrente de mudas infetadas. Embora não se descarte a possibilidade de mudas infetadas terem influenciado no arranjo da doença, a hipótese mais provável é que as infecções ocorreram principalmente através de inóculo primário transmitido por tripes virulíferos entrando nas parcelas, oriundos de reservatórios externos, como as plantas de alface infetadas próximas à área B. Por outro lado, a transmissão secundária planta-a-planta por vetores dentro das parcelas parece ter exercido pouca influência na epidemia, principal mente na área $\mathrm{B}$, uma vez que a agregação de plantas doentes, indicativa desse processo, foi detectada em poucas situações. Resultados similares foram observados na análise do arranjo espacial de vira-cabeça em tomateiro (Lycopersicon esculentum Mill.), pimentão (Capsicum annuum L.) (Gitaitis et al., 1998) e amendoim (Arachis hypogaea L.) (Camann et al., 1995), sendo a limitada dispersão secundária atribuída ao tempo necessário para que o processo de transmissão se complete. A aquisição do vírus pelo vetor é realizada somente no período larval e apenas o adulto tem capacidade de transmiti-lo (Wijkamp et al., 1995), e para as plantas infetadas produzirem inóculo secundário, os tripes têm que produzir larvas que adquiram o vírus, passem pelo período de incubação, pupem e migrem para as plantas sadias como adultos virulíferos, sendo que o tempo requerido para esses eventos pode limitar a quantidade de dispersão secundária. Além disso, a transmissão secundária planta-a-planta de tospovirus por meios mecânicos, como desbrota e outras práticas culturais, embora seja possível (Kumar et al., 1993), não tem sido evidenciada no campo (Gitaitis et al., 1998).

Resultados conflitantes entre as análises de "ordinary runs" e autocorrelação espacial, como verificado nas duas últimas avaliações das parcelas 3 e 4 da área $A$ e nas três últimas avaliações da parcela 4 da área $B$, podem indicar que a ausência de agregação da doença entre plantas imedia- tamente adjacentes, como obtido por "ordinary runs", não é indicativo da ausência de processos espaciais que podem somente ser detectados por análises baseadas em distância (Gottwald et al., 1996). Entretanto, o arranjo da doença em pequenos "clusters", como evidenciado pela análise de autocorrelação espacial, pode indicar um tempo insuficiente para plantas infetadas servirem como fonte para infecções subseqüentes dentro da mesma estação de cultivo. Além disso, a agregação de plantas doentes no final da estação de cultivo, verificado na análise de autocorrelação espacial nas parcelas 3 e 4 da área $\mathrm{A}$ e na parcela 4 da área $\mathrm{B}$, segundo Madden et al. (1982), é sugestiva de dispersão secundária do patógeno.

A ausência de correlação entre incidência da doença e grau de agregação de plantas doentes também foi constatada por Madden et al. (1995). Mudanças no arranjo espacial de plantas doentes no tempo, como verificado em algumas situações no presente estudo, parece ser comum em outros patossistemas envolvendo viroses (Madden et al., 1987; Almeida et al., 1994; Habili \& Nutter, 1997).

No presente estudo, a incidência do vira-cabeça do fumo foi mapeada intensivamente em espaço e a vários períodos de tempo em parcelas experimentais no campo. Apesar da limitada dispersão secundária do GRSV, epidemias de vira-cabeça no fumo podem ser muito severas e progredirem no tempo e no espaço, levando a grandes perdas. $\mathrm{O}$ incremento no desenvolvimento da doença é, provavelmente, devido ao contínuo influxo de grandes quantidades de inóculo primário de tripes virulíferos. Portanto, a adoção de medidas baseadas na sanitização, que reduzem o inóculo inicial do patógeno (Berger, 1988), como destruição de plantas hospedeiras silvestres, plantio em áreas distantes de plantas cultivadas infetadas, uso de mudas sadias produzidas em áreas sem a presença de vetores e da doença, controle de vetores e destruição de plantas de fumo doentes, podem propiciar excelentes resultados no controle integrado de vira-cabeça do fumo em Arapiraca.

\section{AGRADECIMENTOS}

Os autores expressam seus agradecimentos à Coordenação de Aperfeiçoamento de Pessoal de Nível Superior (CAPES) pelo apoio financeiro, à Empresa de Assistência Técnica e Extensão Rural do Estado de Alagoas (EMATER-AL) e à Secretaria da Agricultura de Arapiraca pelo apoio logístico, e aos agricultores de Arapiraca que permitiram a realização do presente estudo em suas propriedades.

\section{REFERÊNCIAS BIBLIOGRÁFICAS}

ALMEIDA, A.M.R., BERGAMIN FILHO, A. \& AMORIM, L. Disease progress of soybean bud blight and spatial pattern of diseased plants. Zeitschrift für Pflanzenkrankheiten und Pflanzenschutz 101:386-392. 1994.

BERGER, R.D. The analysis of effects of control measures 
on the development of epidemics. In: Kranz, J., Rotem, J. (Eds.). Experimental Techniques in Plant Disease Epidemiology. Heidelberg. Springer-Verlag. 1988. pp.137-151.

BURDON, J.J. Diseases and Plant Population Biology. Cambridge. Cambridge University Press. 1987.

CAMANN, M.A., CULBREATH, A.K., PICKERING, J., TODD, J.W. \& DEMSKI, J.W. Spatial and temporal patterns of spotted wilt epidemics in peanut. Phytopathology 85:879-885. 1995.

CAMPBELL, C.L., JACOBI, W.R., POWELL, N.T. \& MAIN, C.E. Analysis of disease progression and the randomness of occurrence of infected plants during tobacco black shank. Phytopathology 74:230-235. 1984.

CAMPBELL, C.L. \& MADDEN, L.V. Introduction to Plant Disease Epidemiology. New York. John Willey \& Sons. 1990.

GITAITIS, R.D., DOWLER, C.C. \& CHALFANT, R.B. Epidemiology of tomato spotted wilt in pepper and tomato in southern Georgia. Plant Disease 82:752-656. 1998.

GODOY, C.V. \& SALGADO, C.L. Doenças do fumo (Nicotiana tabacum L.). In: Kimati, H., Amorim, L., Bergamin Filho, A., Camargo, L.E.A. \& Rezende, J.A.M. (Eds.) Manual de Fitopatologia: Doenças das Plantas Cultivadas. São Paulo. Agronômica Ceres. 1997. v.2, pp.411-420.

GOTTWALD, T.R., CAMBRA, M., MORENO, P., CAMARASA, E. \& PIQUER, J. Spatial and temporal analyses of citrus tristeza virus in eastern Spain. Phytopathology 86:45-55. 1996.

GOTTWALD, T.R., RICHIE, S.M. \& CAMPBELL, C.L. LCOR2 - Spatial correlation analysis software for the personal computer. Plant Disease 76:213-215. 1992.

HABILI, N. \& NUTTER, JR. F.W. Temporal and spatial analysis of grapevine leafroll-associated virus 3 in Pinot Noir grapevines in Australia. Plant Disease 81:625-628. 1997.

IBGE. SIDRA 97 - Sistema IBGE de recuperação automática. Rio de Janeiro: Instituto Brasileiro de Geografia e Estatística, 2000. (http://www.sidra. ibge.gov.br - versão 21/04/2001).

JEGER, M.J. Mathematical analysis and modeling of spatial aspects of plant disease epidemics. In: Kranz, J. (Ed.).
Epidemics of Plant Diseases: Mathematical Analysis and Modeling. 2. ed. Heidelberg. Springer-Verlag. 1990. pp.53-95.

KUMAR, N.K.K., ULLMAN, D.E. \& CHO, J.J. Evaluation of Lycopersicon germ plasm for tomato spotted wild tospovirus resistance by mechanical and thrips transmission. Plant Disease 77:938-941. 1993.

MADDEN, L.V., LOUIE, R., ABT, J.J. \& KNOKE, J.K. Evaluation of tests for randomness of infected plants. Phytopathology 72:195-198. 1982.

MADDEN, L.V., NAULT, L.R., MURRAL, D.J. \& APELT, M.R. Spatial pattern analysis of incidence of aster yellows disease in lettuce. Researches on Population Ecology 37:279-289. 1995.

MADDEN, L.V., PIRONE, T.P. \& RACCAH, B. Analysis of spatial patterns of virus-diseased tobacco plants. Phytopathology 77:1409-1417. 1987.

POZZER, L., RESENDE, R.O., LIMA, M.I., KITAJIMA, E.W., GIORDANO, L.B. \& DE ÁvilA, A.C. Tospovírus: uma visão atualizada. Revisão Anual de Patologia de Plantas 4:95-148. 1996.

SIBERSCHMIDT, K.M. A doença de vira-cabeça do fumo. O Biológico 3:183-184. 1937.

SILVA, J.N., PIO-RIBEIRO, G., ANDRADE, G.P., ANDRADE, A.M.X., SONKO, B., MEDEIROS, R.P., LIMA, L.F.N. \& ALBUQUERQUE, H.C. Levantamento de vírus que infectam fumo no município de Arapiraca - AL. Fitopatologia Brasileira 24:360. 1999 (Resumo).

VAN DE WETERING, F., GOLBACH, R. \& PETERS, D. Tomato spotted wilt tosporvirus ingestion by first instar larvae of Frankliniella occidentalis is a prerequisite for transmission. Phytopathology 86:900-905. 1996.

WIJKAMP, I., ALMARZA, N., GOLDBACH, R. \& PETERS, D. Distinct levels of specificity in thrips transmission of tospoviruses. Phytopathology 85:1069-74. 1995.

WIJKAMP, I., VAN LENT, J., KORMELINK, R., GOLDBACH, R. \& PETERS, D. Multiplication of tomato spotted wilt virus in its insect vector, Frankliniella occidentalis. Journal of General Virology 74:341-349. 1993.

XIAO, C.L., HAO, J.J. \& SUBBARAO, K.V. Spatial patterns of microesclerotia of Verticillium dahliae in soil and Verticillium wilt of cauliflower. Phytopathology 87:325331. 1997. 